\title{
Visible Sensitization for Non-Fullerene Polymer Solar Cells Using a Wide Bandgap Polymer
}

\author{
Yanbin Wang ${ }^{1}$, Hyung Do Kim², Biaobing Wang ${ }^{1 *}$, and Hideo Ohkita ${ }^{2 * *}$ \\ ${ }^{1}$ Jiangsu Key Laboratory of Environmentally Friendly Polymeric Materials, School of \\ Materials Science and Engineering, Jiangsu Collaborative Innovation Center of \\ Photovolatic Science and Engineering, Changzhou University, Changzhou, Jiangsu, \\ 213164, People's Republic of China \\ 2 Department of Polymer Chemistry, Graduate School of Engineering, Kyoto University, \\ Katsura, Nishikyo, Kyoto 615-8510, Japan \\ *biaobing@cczu.edu.cn \\ **ohkita@photo.polym.kyoto-u.ac.jp
}

\begin{abstract}
Non-fullerene polymer solar cells based on blends of a middle-bandgap polymer, poly[(2,6-(4,8-bis(5-(2-ethylhexyl)thiophen-2-yl)benzo[1,2- $b$ :4,5- $\left.b^{\prime}\right]$ dithiophene)-co-(1,3di(5-thiophene-2-yl)-5,7-bis(2-ethylhexyl)-benzo[1,2-c:4,5-c']dithiophene-4,8-dione)] (PBDB-T) and a low-bandgap non-fullerene derivative (IT-M) exhibit improved short-circuit current density $\left(J_{\mathrm{SC}}\right)$ by incorporating a wide-bandgap polymer, poly [5, ','bis(2-butyloctyl)(2,2'-bithiophene)-4,4'-dicarboxylate-alt-5,5'-2,2'-bithiophene] (PDCBT). This is mainly due to the enhanced absorption efficiency in the visible region for ternary devices. As a result, the power conversion efficiency (PCE) was increased up to $11.2 \%$ for the ternary blend device.
\end{abstract}

Keywords: Visible sensitization, Non-fullerene, Polymer solar cells, Wide-bandgap polymer, Ternary blend

\section{Introduction}

Polymer solar cells have made rapid progress in the last decade and have shown a power conversion efficiency (PCE) of more than 10\% [1-7]. However, there is still room for improvement in the photocurrent generation. This is mainly due to spectral mismatch between the absorption spectrum of the photoactive layer and the terrestrial solar radiation. In other words, it is difficult to effectively harvest photons both in the visible and near-infrared (near-IR) region simultaneously because of narrow absorption bandwidth of organic materials. In order to overcome such limitation, two approaches have been proposed recently. One is non-fullerene polymer solar cells, in which nonfullerene acceptors can harvest the solar light much more effectively than fullerene acceptors [8-16]. The other is ternary blend polymer solar cells, in which additional third materials can harvest the solar light that cannot be absorbed by binary blends, as reported previously [17-31]. Both approaches have succeeded in improving the photovoltaic performance of polymer solar cells.

In this study, we have fabricated non-fullerene ternary blend polymer solar cells by combining these two approaches. More specifically, a widebandgap polymer, poly[5,5'-bis(2-butyloctyl)(2,2'-bithiophene)-4,4'-dicarboxylate-alt-5,5'-2,2'bithiophene] (PDCBT, Figure 1a) was incorporated into a binary blend based on a middle-bandgap polymer, poly[(2,6-(4,8-bis(5-(2-ethylhexyl)thiophen-2-yl) benzo[1,2-b:4,5- $\left.b^{\prime}\right]$ dithiophene)-co(1,3-di(5-thiophene-2-yl)-5,7-bis(2-ethylhexyl)benzo[1,2-c:4,5-c']dithiophene-4,8-dione)] (PBDB-T, Fig. 1b) and a low-bandgap non-fullerene acceptor (IT-M, Fig. 1c) to improve the lightharvesting efficiency in the visible range. As a result, the short-circuit current density $\left(J_{\mathrm{SC}}\right)$ was enhanced, and thus the power conversion efficiency (PCE) was also improved from $10.2 \%$ for the binary blend device to $11.2 \%$ for the ternary blend device. 


\section{Experimental}

\subsection{Materials}

All the materials employed as active and buffer layers were purchased from Solarmer Materials Inc.: PDCBT (number-averaged molecular weight, $\left.M_{\mathrm{n}}=24,000 \mathrm{~g} \mathrm{~mol}^{-1}\right)$, PBDB-T $\left(M_{\mathrm{n}}=31,000 \mathrm{~g}\right.$ $\left.\mathrm{mol}^{-1}\right)$, IT-M, poly(3,4-ethylenedioxythiophene): poly(4-styrenesulfonate) (PEDOT:PSS, H.C. Starck Clevios PH500), and poly[(9,9-bis(3- $((N, N-$ dimethyl)- $N$-ethylammonium)propyl)-2,7-fluorene)-alt-2,7-(9,9-dioctylfluorene)] (PFN-Br). These materials were used without further purification.



Fig. 1. Chemical structures of materials employed in this study: a) PDCBT, b) PBDB-T, and c) IT-M. d) Energy diagrams for these three materials. The figures represent HOMO (lower) and LUMO (upper) energy levels.

\subsection{Device fabrication}

Non-fullerene polymer solar cells were fabricated as follows. Indium-tin-oxide (ITO)-coated glass substrates (10 $\Omega$ per square) were rinsed by ultrasonication with toluene, acetone, and then ethanol for 15 min each. The cleaned substrates were dried under nitrogen gas, and then treated with a $\mathrm{UV}-\mathrm{O}_{3}$ cleaner (Nippon Laser \& Electronics, NLUV253S) for $30 \mathrm{~min}$. A hole-transporting buffer layer (40 nm) of PEDOT:PSS was spin-coated onto the cleaned substrates at $3000 \mathrm{rpm}$, and then dried on a hot plate at $140{ }^{\circ} \mathrm{C}$ for $10 \mathrm{~min}$ in air. Prior to the spin-coating, the solution of PEDOT:PSS was filtered with a PTFE syringe filter (pore size: 0.45 $\mu \mathrm{m})$. The blend active layer was prepared on ITO/PEDOT:PSS substrate by spin-coating at 2200 $\mathrm{rpm}$ for $60 \mathrm{~s}$ in the nitrogen atmosphere, and subsequently annealed on a hot plate at $160{ }^{\circ} \mathrm{C}$ for $10 \mathrm{~min}$. A solution of PBDB-T/IT-M/PDCBT blend was prepared by dissolving donor polymers and IT-M $(1: 1, \mathrm{w} / \mathrm{w})$ with a composition ratio of $x$ : $1: 1-x \quad \mathrm{mg}$ in $1 \mathrm{~mL}$ of chlorobenzene with $0.5 \%$ volume ratio of 1,8-diiodooctane (DIO). The blend solution was stirred at $80{ }^{\circ} \mathrm{C}$ overnight. Note that the weight fraction of the PDCBT was optimized in the range from 5 to $15 \mathrm{wt} \%$. The thickness of blend film was $\sim 100 \mathrm{~nm}$. The PFNBr buffer layer $(\sim 5 \mathrm{~nm})$ was prepared on the active layer by spin-coating at $3000 \mathrm{rpm}$ for $60 \mathrm{~s}$ from a solution of PFN-Br $(0.5 \mathrm{mg})$ in anhydrous methanol (1 mL, Wako Pure Chemical Industries Ltd.). Finally, $100 \mathrm{~nm}$ of aluminum top electrode was thermally evaporated on top of the PFN-Br layer under vacuum at $2.5 \times 10^{-4} \mathrm{~Pa}$. Consequently, the device layered structure obtained was as follows: ITO/PEDOT:PSS/PDCBT:PBDB-T:IT-M/PFN$\mathrm{Br} / \mathrm{Al}$. The effective area of device was $0.07 \mathrm{~cm}^{2}$.

\subsection{Measurement}

$J-V$ characteristics were measured with a directcurrent (DC) voltage and current source/monitor (Keithley, 2611B) in the dark and under the illumination with AM1.5G simulated solar light with $100 \mathrm{~mW} \mathrm{~cm}{ }^{-2}$. The light intensity was corrected with a calibrated silicon photodiode reference cell (Bunkoukeiki, BS-520). External quantum efficiency (EQE) spectra were measured with a spectral response measurement system (Bunkoukeiki, ECT-250D). The power of the incident monochromatic light was kept under 0.05 $\mathrm{mW} \mathrm{cm}{ }^{-2}$, which was measured with a calibrated silicon reference cell (Bunkoukeiki, BS-520BK). Absorption and photoluminescence (PL) spectra were measured with a spectrophotometer (Hitachi, U-4100) and a spectrofluorometer (Horiba Jobin Yvon, NanoLog), respectively. The film surface morphology was measured with an atomic force microscope (AFM, Shimadzu, SPM-9700) in a tapping mode using a high resolution cantilever (MikroMasch, Hi'Res-C14/Cr-Au) with a force 
constant of $\approx 5 \mathrm{~N} \mathrm{~m}^{-1}$ and a resonance frequency of $160 \mathrm{kHz}$

\section{Results and discussion}

Figure 2 shows the absorption spectra of each neat film and blend film. As shown in Fig. 2a, the wide bandgap PDCBT, the middle-bandgap PBDB$\mathrm{T}$, and the low-bandgap IT-M exhibited the absorption peaks at around $550 \mathrm{~nm}, 630 \mathrm{~nm}$, and $700 \mathrm{~nm}$, respectively. The PBDB-T/IT-M binary blend film exhibited an absorption valley from 400 to $550 \mathrm{~nm}$. As shown in Fig. 2b, this small absorption can be enhanced by incorporating widebandgap polymer PDCBT into the binary blend, suggesting that the ternary blend film can harvest the solar light from the visible to near-IR range because of the complementary absorption spectra.

Figure 3 shows the AFM height images of PBDBT/IT-M binary blend film and PBDB-T/IT$\mathrm{M} / \mathrm{PDCBT}$ ternary blend film with $10 \mathrm{wt} \%$ PDCBT.



Fig. 2. a) Absorption spectra of PDCBT (solid line), PBDB-T (broken line), and IT-M (grey line) neat films. b) Absorption spectra of PBDB-T/IT-M binary (broken line) and PBDB-T/IT-M/PDCBT ternary (solid line) blend films covered with $\mathrm{Al}$, which were measured in the reflection mode. The weight fraction of PDCBT was $10 \mathrm{wt} \%$ in the ternary blend. a)

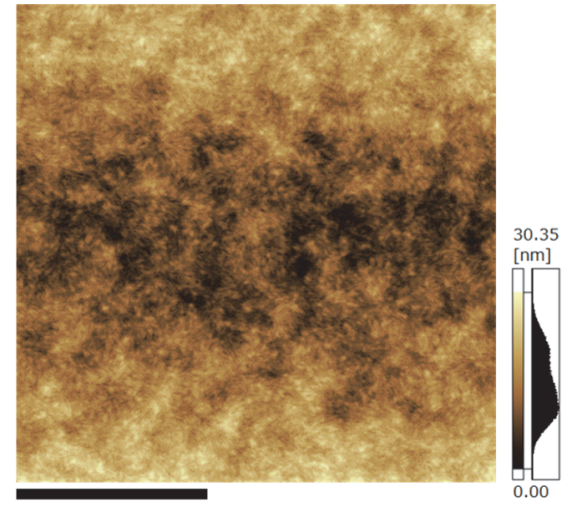

b)

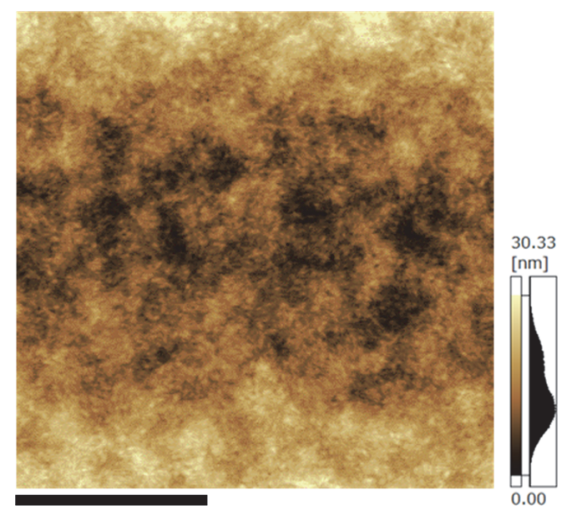

Fig. 3. AFM height images $(5 \mu \mathrm{m} \times 5 \mu \mathrm{m})$ of (a) PBDB-T/IT-M binary and (b) PBDB-T/ITM/PDCBT ternary blend films. The weight fraction of PDCBT was $10 \mathrm{wt} \%$ in the ternary blend. The scale bar corresponds to a length of $2 \mu \mathrm{m}$.

The root-mean-square surface roughness was estimated to be $5.3 \mathrm{~nm}$ for PBDB-T/IT-M binary blend and $5.6 \mathrm{~nm}$ for PBDB-T/IT-M/PDCBT ternary blend films, indicating a smooth and fine surface morphology. Furthermore, we found that the morphology of the PBDB-T/IT-M/PDCBT ternary blend is very similar to that of the PBDBT/IT-M binary reference blend on a scale of micrometers. This finding suggests that the incorporation of PDCBT into the PBDB-T/IT-M blend does not cause any significant changes in the surface morphology.

Figure 4 shows the $J-V$ characteristics of PBDBT/IT-M binary blend solar cells and PBDB-T/ITM/PDCBT ternary blend solar cells with $10 \mathrm{wt} \%$ PDCBT. As summarized in Table 1, the PBDBT/IT-M binary reference device exhibited a $J_{\mathrm{SC}}$ of $17.16 \mathrm{~mA} \mathrm{~cm}^{-2}$, a $V_{\mathrm{OC}}$ of $0.933 \mathrm{~V}$, an FF of $63.5 \%$, and a PCE of $10.2 \%$, which is comparable to that reported before [32]. By adding $10 \mathrm{wt} \%$ of a widebandgap polymer PDCBT into the PBDB-T/IT-M binary blend, the $J_{\mathrm{SC}}$ was increased up to $17.24 \mathrm{~mA}$ $\mathrm{cm}^{-2}$. On the other hand, no change was observed for the open-circuit voltage $\left(V_{\mathrm{OC}}\right)$. This is 


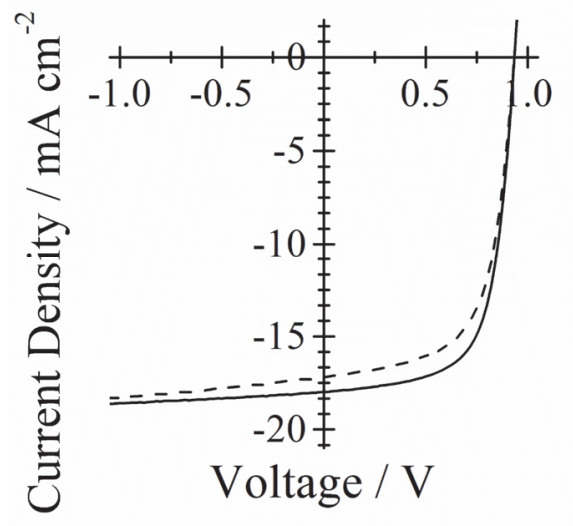

Fig. 4. $J-V$ characteristics of PBDB-T/IT-M binary blend (broken line) and PBDB-T/IT-M/PDCBT ternary blend (solid line) solar cells. The weight fraction of PDCBT was $10 \mathrm{wt} \%$ in the ternary blend.

probably because there is no big difference in the highest occupied molecular orbital level between PBDB-T and PDCBT as shown in Fig. 1d $[3,33]$. The fill factor (FF) was slightly increased. As a result, the overall PCE was improved by $10 \%$ from $10.2 \%$ for the binary blend device to $11.2 \%$ for the ternary blend device, which is mainly ascribed to the enhancement in $J_{\mathrm{SC}}$. With addition of more than $10 \mathrm{wt} \%$ of PDCBT, the $J_{\mathrm{SC}}$ decreased and hence the overall photovoltaic performance was also degraded. This is probably because bicontinuous interpenetrating networks of PBDBT/IT-M was disturbed due to the high crystallinity of PDCBT [33].

In order to address the origin of the increase in $J_{\mathrm{SC}}$, we measured the EQE spectra of PBDB-T/ITM/PDCBT ternary blend and PBDB-T/IT-M binary blend solar cells. As shown in Fig. 5, with addition of $10 \mathrm{wt} \%$ of PDCBT, the EQE signal was enhanced in the wavelength range from 400 to 650

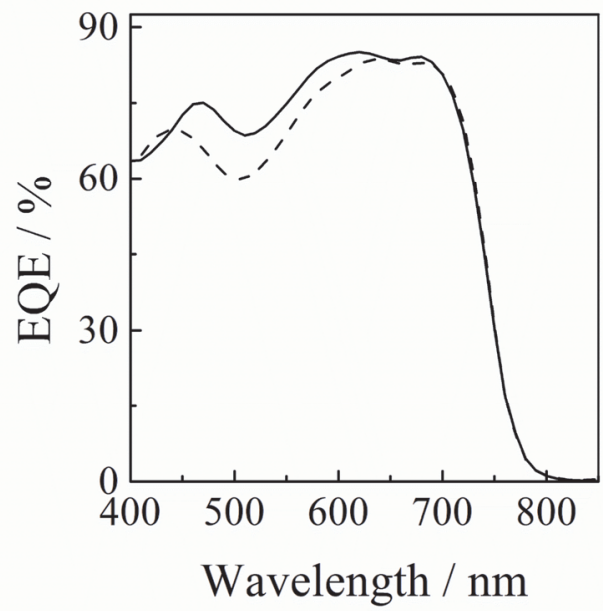

Fig. 5. EQE spectra of PBDB-T/IT-M binary blend (broken lines) and PBDB-T/IT-M/PDCBT ternary blend (solid lines) solar cells. The weight fraction of PDCBT was $10 \mathrm{wt} \%$ in the ternary blend.

$\mathrm{nm}$ by addition of the wide-bandgap polymer PDCBT into the PBDB-T/IT-M reference binary blend. The $J_{\mathrm{SC}}{ }^{\text {calc }}$ calculated from the EQE and solar spectra is in good agreement with the $J_{\mathrm{SC}}$ directly measured from the $J-V$ curve as shown in Table 1. Furthermore, the EQE spectra are consistent with the absorption spectra measured in the reflectance mode as shown in Fig. 2b. Such agreements show that the photocurrent improvement in the ternary blend device is primarily ascribed to the increased absorption efficiency due to the visible sensitization by PDCBT.

\section{Conclusion}

We have demonstrated efficient ternary blend solar cells consisting of a middle-bandgap polymer PBDB-T, a low-bandgap non-fullerene acceptor IT$\mathrm{M}$, and a wide-bandgap polymer PDCBT. With the incorporation of wide bandgap polymer PDCBT

Table 1. Photovoltaic parameters of ternary blend solar cells with different weight fractions of PDCBT.

\begin{tabular}{cccccc}
\hline PBDB-T : IT-M : PDCBT & $J_{\mathrm{SC}} / \mathrm{mA} \mathrm{cm}^{-2}$ & $J_{\mathrm{SC}}$ calc $/ \mathrm{mA} \mathrm{cm}^{-2}$ & $V_{\mathrm{OC}} / \mathrm{V}$ & $\mathrm{FF} / \%$ & $\mathrm{PCE} / \%$ \\
\hline $1.0: 1.0: 0 \quad(0 \mathrm{wt} \%)$ & 17.16 & 16.72 & 0.933 & 63.5 & 10.17 \\
$0.9: 1.0: 0.1(5 \mathrm{wt} \%)$ & 17.73 & 17.16 & 0.929 & 66.4 & 10.94 \\
$0.8: 1.0: 0.2(10 \mathrm{wt} \%)$ & 17.97 & 17.52 & 0.930 & 66.7 & 11.2 \\
$0.7: 1.0: 0.3(15 \mathrm{wt} \%)$ & 16.81 & 16.00 & 0.927 & 59.5 & 9.27 \\
\hline
\end{tabular}


into PBDB-T/IT-M binary blends, the photocurrent was clearly improved in the visible range because of the complementary absorption of the photoactive layers while negligible change in $V_{\mathrm{OC}}$ and $\mathrm{FF}$ were observed. As a result, the overall PCE of PBDBT/IT-M/PDCBT ternary blend solar cells was improved up to $11.2 \%$.

\section{Acknowledgments}

This work was partly supported by the Natural Science Foundation of Jiangsu Province (BK20160280), Double Plan of Jiangsu Province, and the Japan Science and Technology Agency (JST) ALCA program (Solar Cell and Solar Energy Systems). Note that Yanbin Wang and Hyung Do Kim contributed equally to this work.

\section{References}

1. X. Xu, T. Yu, Z. Bi, W. Ma, Y. Li, and Q. Peng, Adv. Mater., 30 (2018) 1703973.

2. F. Zhao, S. Dai, Y. Wu, Q. Zhang, J. Wang, L. Jiang, Q. Ling, Z. Wei, W. Ma, W. You, C. Wang, and X. Zhan, Adv. Mater., 29 (2017) 1700144.

3. W. Zhao, S. Li, H. Yao, S. Zhang, Y. Zhang, B. Yang, and J. Hou, J. Am. Chem. Soc., 139 (2017) 7148.

4. S. Li, L. Ye, W. Zhao, S. Zhang, S. Mukherjee, H. Ade, and J. Hou, Adv. Mater., 28 (2016) 9423.

5. V. Vohra, K. Kawashima, T. Kakara, T. Koganezawa, I. Osaka, K. Takimiya, and H. Murata, Nat. Photon., 9 (2015) 403.

6. Z. He, B. Xiao, F. Liu, H. Wu, Y. Yang, S. Xiao, C. Wang, T. P. Russell, and Y. Cao, Nat. Photon., 9 (2015) 174.

7. Y. Liu, J. Zhao, Z. Li, C. Mu, W. Ma, H. Hu, K. Jiang, H. Lin, H. Ade, and H. Yan, Nat. Commun., 5 (2014) 5293.

8. J. Hou, O. Inganäs, R. H. Friend, and F. Gao, Nat. Mater., 17 (2018) 119.

9. S. Li, W. Liu, C. Li, M. Shi, and H. Chen, Small, 13 (2017) 1701120.

10. Z. Liu, Y. Wu, Q. Zhang, and X. Gao, J. Mater. Chem. A, 4 (2016) 17604.

11. H. Benten, D. Mori, H. Ohkita, and S. Ito, $J$. Mater. Chem. A, 4 (2016) 5340.

12. C. B. Nielsen, S. Holliday, H. Chen, S. J. Cryer, and I. McCulloch, Acc. Chem. Res., 48 (2015) 2803.

13. S. Ito, T. Hirata, D. Mori, H. Benten, L. Lee, and
H. Ohkita, J. Photopolym. Sci. Technol., 26 (2015) 175.

14. Y. Cai, L. Huo, and Y. Sun, Adv. Mater, 29 (2017) 1605437.

15. Y. Lin, Q. He, F. Zhao, L. Huo, J. Mai, X. Lu, C. Su, T. Li, J. Wang, J. Zhu, Y. Sun, C. Wang, and X. Zhan, J. Am. Chem. Soc., 138 (2016) 2973.

16. Y. Lin, F. Zhao, Q. He, L. Huo, Y. Wu, T. C. Parker, W. Ma, Y. Sun, C. Wang, D. Zhu, A. J. Heeger, S. R. Marder, and X. Zhan, J. Am. Chem. Soc., 138 (2016) 4955.

17. H. Li, K. Lu, and Z. Wei, Adv. Energy Mater, 7 (2017) 1602540.

18. H. Huang, L. Yang, and B. Sharma, J. Mater. Chem. A, 5 (2017) 11501.

19. Q. An, F. Zhang, J. Zhang, W. Tang, Z. Deng, and B. Hu, Energy Environ. Sci., 9 (2016) 281.

20. H. Benten, T. Nishida, D. Mori, H. Ohkita, and S. Ito, J. Photopolym. Sci. Technol., 29 (2016) 537.

21. T. Liu, Y. Guo, Y. Yi, L. Huo, X. Xue, X. Sun, H. Fu, W. Xiong, D. Meng, Z. Wang, F. Liu, T. P. Russell, and Y. Sun, Adv. Mater, 28 (2016) 10008.

22. L. Lu, M. A. Kelly, W. You, and L. Yu, Nat. Photon., 9 (2015) 491.

23. H. Xu, T. Wada, H. Ohkita, H. Benten, and S. Ito, Sci. Rep., 5 (2015) 9321.

24. S. Honda, S. Yokoya, H. Ohkita, H. Benten, and S. Ito, J. Phys. Chem. C, 115 (2011) 11306.

25. H. Xu, H. Ohkita, Y. Tamai, H. Benten, and S. Ito, Adv. Mater., 27 (2015) 5868.

26. Y. Wang, H. Ohkita, H. Benten, and S. Ito, Phys. Chem. Chem. Phys., 17 (2015) 27217.

27. Y. Wang, B. Zheng, Y. Tamai, H. Ohkita, H. Benten, and S. Ito, J. Electrochem. Soc., 161 (2014) D3093.

28. S. Honda, T. Nogami, H. Ohkita, H. Benten, and S. Ito, ACS Appl. Mater. Interfaces, 1 (2009) 804.

29. S. Honda, H. Ohkita, H. Benten, and S. Ito, $A d v$. Energy Mater., 1 (2011) 588.

30. T. Ameri, P. Khoram, J. Min, and C. J. Brabec, Adv. Mater., 25 (2013) 4245.

31. H. Xu, T. Wada, H. Ohkita, H. Benten, and S. Ito, Electrochim. Acta, 100 (2013) 214.

32. W. Zhao, S. Li, S. Zhang, X. Liu, and J. Hou, Adv. Mater., 29 (2017) 1604059.

33. M. Zhang, X. Guo, W. Ma, H. Ade, and J. Hou, Adv. Mater., 26 (2014) 5880. 